\title{
JOGOS DIDÁTICOS COMO AUXÍLIO PARA O ENSINO- APRENDIZAGEM DA MATEMÁTICA
}

\section{ARTIGO ORIGINAL}

SOUZA, Adriane Oliveira de ${ }^{1}$

BEZERRA, Cynara Carmo ${ }^{2}$

SILVA, Clariane Pontes da ${ }^{3}$

SOUZA, Adriane Oliveira de. BEZERRA, Cynara Carmo. SILVA, Clariane Pontes da. Jogos didáticos como auxílio para o ensino-aprendizagem da matemática. Revista Científica Multidisciplinar Núcleo do Conhecimento. Ano 05, Ed. 03, Vol. 07, pp. 57-68. Março de 2020. ISSN: 2448-0959

\section{RESUMO}

O objetivo dessa pesquisa é conhecer as principais causas que podem levar o aluno a ter dificuldades em aprender a matemática e procurar, a partir da pesquisa bibliográfica, embasamento para a prática pedagógica, para, assim, trabalhar diferentes jogos e brincadeiras, visando, com isso, a introdução do aprendizado matemático bem como o desenvolvimento do raciocínio lógico-matemático do aluno para possíveis soluções ou amenização do problema. A metodologia de ensino na aprendizagem matemática que conhecemos hoje nas escolas regulares da rede pública de ensino é voltada, diretamente, às aulas expositivas e dialogadas, sem a utilização de recursos necessários para estimular o aluno a se interessar pela disciplina. Durante o período acadêmico, na fase de observação dos alunos na sala

\footnotetext{
${ }^{1}$ Graduada Em Matemática, Especialização Em Ensino Da Matemática E Física, Mestranda Em Ciência Da Educação.

2 Doutora Em Biotecnologia.

${ }^{3}$ Graduada Em Ciências Biológicas.
} 
de aula, detectou-se a grande carência da aprendizagem, pois a metodologia baseava-se no tradicionalismo. A metodologia se pauta na observação e dialética, na pesquisa bibliográfica e no estudo de caso para esclarecimento da problemática. Os instrumentos de coleta de dados utilizados foram a observação assistemática e participativa e a coletiva intra e extraescolar. Foram registrados os trabalhos na forma de relatórios, e, para isso, foi dado suporte para elaboração e interpretação na etapa da análise de dados. Neste artigo, foram resumidos alguns aspectos importantes da aprendizagem do ensino da matemática. Aqui serão relatadas algumas experiências vividas em sala de aula com a aplicação de jogos didáticos para o ensino da Matemática em uma turma do $7^{\circ}$ ano do Ensino Fundamental, na cidade de Parintins/AM, na Escola Estadual Charles Garcia.

Palavras-chave: Raciocínio lógico, jogos e brincadeiras, estratégias matemáticas.

\section{INTRODUÇÃO}

$\mathrm{O}$ artigo tem como finalidade mostrar os resultados de uma pesquisa realizada em uma escola da rede municipal de ensino da Cidade de Parintins/AM e foi direcionada para alunos e professores do $7^{\circ}$ ano da Escola Municipal Charles Garcia. Com os discentes, teve-se como objetivo obter dados em relação ao rendimento destes antes e após a aplicação de Jogos Didáticos no ensino da Matemática e, quanto aos docentes, pretendeu-se conhecer as principais dificuldades encontradas no ensinoaprendizagem da matemática dentro da sala de aula assim como saber quais os conteúdos que os alunos apresentavam maiores dificuldades de aprendizagem. Conforme a pesquisa e coleta de dados durante o período de investigação, detectamos a grande carência na afetividade e aprendizagem matemática. Isso revela que a maneira que o professor trabalha é de grande importância para o aluno aprender ou não.

A partir da problemática elencada, com este artigo procuramos mostrar alguns tópicos importantes que chamam a atenção do educador, sobretudo propõe-se refletir sobre qual seria a lógica da inserção dos jogos, brincadeiras e contextualização da matemática para o desenvolvimento da aprendizagem no aluno, mostrando, para 
tanto, que para lidar com tal deficiência existe algumas soluções, sendo o uso de algumas estratégias pedagógicas uma abordagem eficiente. Uma delas seriam os jogos e brincadeiras matemáticos como instrumento de auxílio para a aprendizagem. Silva (2004) destaca em seu livro "Jogos Educativos" que jogos e brincadeiras estimulam o aluno a desenvolver o raciocínio logico- matemático, e, esse recurso, pode ser utilizado para deixar as aulas dinâmicas e de fácil compreensão.

Diante do exposto, torna-se válido ressaltar, ainda, segundo o estudo de Aranão (2004), que o ensino da matemática a partir das brincadeiras e dos jogos, deve, principalmente, despertar o interesse dos alunos pela disciplina e, ainda, cabe, ao professor, o oferecimento de subsídios que os faça ter interesse palas aulas, pelos jogos e pelas brincadeiras, fazendo, assim, com que o aluno crie boas perspectivas, deposite confiança na aprendizagem e que venha a frequentar as aulas com assiduidade. Sabemos que os jogos e brincadeiras são de grande valia para o aluno, mas não é um recurso que se possa usar frequentemente pra explicar conteúdo matemático que venha a exigir cálculos e fórmulas, e, com isso, voltamos a assegurar que os jogos e brincadeiras de matemáticas atuam como uma ferramenta auxiliadora fundamental para o ensino aprendizagem.

\section{IMPORTÂNCIA DOS JOGOS DIDÁTICOS NO PROCESSO ENSINO- APRENDIZAGEM}

É sabido, segundo a literatura, que os jogos quando aliados à resolução de problemas podem atuar como uma importante ferramenta para o desenvolvimento da aprendizagem dos conteúdos matemáticos. Neste artigo procuramos discutir a possibilidade de utilizar os jogos de estratégia para desenvolver os conteúdos matemáticos trabalhados nas séries do ensino fundamental. De acordo com Carraher e Shlielmann (1994, p. 12) "a aprendizagem da matemática na sala de aula é um momento de interação entre a matemática organizada pela comunidade cientifica (...), e a matemática como atividade humana". Uma das formas para melhorar a aprendizagem utilizada pelo educador é contextualizar o cotidiano e a realidade nas 
quais esses alunos vivenciam, e, dessa forma, os alunos precisam estar em contato com conteúdos significativos para que essa aprendizagem ocorra.

É de fundamental importância que o educador crie e desperte, em seus alunos, a motivação para que eles possam despertar a vontade de desenvolver, criar, participar pela construção de seu próprio conhecimento. Segundo Paulo Freire (1996, p. 52) "saber que ensinar não é transmitir conhecimento, mas criar possibilidades para sua própria produção ou sua construção". Incentivar os alunos a estudar a Matemática por meio dos jogos e brincadeiras pode ser a iniciativa para a construção do conhecimento significativo na sua evolução cognitiva. Por estarem presentes no cotidiano escolar e extraescolar, os jogos e brincadeiras permitem explorar esses momentos de prazer e imaginação, desenvolvendo, assim, as capacidades de raciocínio logico-matemático, como, também, o desenvolvimento afetivo-físico.

Ensinar por meio de jogos é um caminho para o educador desenvolver aula mais interessante, descontraída e dinâmica podendo competir em igualdade de condições com os inúmeros recursos a que o aluno tem acesso fora da escola despertando ou estimulando sua vontade de frequentar com assuidade a sala de aula e incentivando seu desenvolvimento ensino aprendizagem, já que e aprende e se diverte, simultaneamente (SILVA, 2004, p. 26).

Dessa forma, é necessário que partamos, neste estudo, do pressuposto de que o professor precisa conhecer a história da matemática para que, assim, seja possível obter subsídios teóricos a fim de buscar embasamento para a sua prática pedagógica para, então, torná-las mais atraentes bem como para que seja possível proporcionar o contato com jogos e brincadeiras educativos no aprendizado matemático para que, então, o aluno desenvolva o seu intelecto. Agindo assim o docente fará com que o aluno absorva melhor o conteúdo relacionado a matemática com o cotidiano. Com isso, supomos que os professores devem explorar mais os materiais pedagógicos que existem nas dependências da escola, aproveitando o conhecimento matemático por meio dos jogos didáticos para construir o conhecimento. 
Teorias das mais complexas contadas pelos matemáticos mais extraordinários sobrevoavam a mente humana sobre a origem desta ciência. Alguns relatos nos narram que a Matemática foi criada a partir dos primeiros seres racionais há milhões de anos, com intuito de inventar uma lei sobre todas as outras que pudesse impor regras e ajudar na resolução de questões lógicas. Os nomes mais expressivos na Matemática surgiram ainda antes de Cristo e foram responsáveis por invenções, fórmulas, regras, teoremas, soluções e cálculos. Portanto, tudo que conhecemos hoje em relação à Matemática, como ciência, vem do berço da história antiga, de homens que ao mesmo tempo que se descobriam, criavam, inventavam e testavam novas formas e diretrizes para conduzir sua história.

\section{A INCLUSÃO DE JOGOS E BRINCADEIRAS NO ENSINO APRENDIZAGEM DA MATEMÁTICA}

A Matemática é, antes de tudo, uma disciplina que requer atenção e exige um modo a mais de pensar para que a sua aprendizagem se torne mais eficaz e significativa. Com isso, quanto mais forem exploradas as técnicas para o desenvolvimento das habilidades intelectuais dos alunos, mais viáveis serão suas chances de compatibilidades extras escolares. O aluno apresenta inúmeras características e uma delas é a curiosidade de aprender o novo. Logo, proporcionar brincadeiras e jogos que envolvam o aprendizado Matemático possibilitará que ele desenvolva conceitos, operações, socialização, criação, construção do novo e outras noções matemáticas que podem ser construídas por esses discentes.

Nesse contexto, é válido reiterar que o aluno ao ingressar na escola, carrega, consigo, isto é, em sua essência, a Matemática vivenciada no convívio diário do espaço social que é absorvida por meio de observações de leitura do mundo. Então, estudar Matemática, na escola, significa continuar com o processo de moldar o conhecimento já adquirido. Com isso, a partir de jogos e brincadeiras, os alunos internalizam com mais eficácia os conceitos matemáticos e esse processo não pode ser dar, apenas, com o uso de livros didáticos, pois é por meio da inclusão da disciplina nos jogos que 
os alunos conseguirão assimilar com rapidez, de forma satisfatória e prazerosa, a associação com objetos que lhes foram propostos.

A utilização do jogo potencializa a exploração e a construção do conhecimento, por contar com motivação interna, típica do lúdico, mais o trabalho pedagógico requerem a oferta de estímulos externos e a influência de parceiros bem como a sistematização de conceitos em outras situações que não jogos(...) (KISHIMOTO apud LUCENA, 2004, p. 42).

Com essas afirmativas e diante do contexto apresentado é inevitável a utilização dos jogos e brincadeiras na ação pedagógica, pois, como reiterado, melhoram a reciprocidade do aluno com as noções matemáticas, uma vez que aprendem brincando e, com isso, desenvolvem o concreto a partir do imaginário, fazendo, assim, uma ligação do aprendizado com o conhecimento matemático. Assim sendo, podemos dizer que a Matemática não é somente uma ciência, mas também uma habilidade essencial para a sobrevivência na sociedade complexa que vivemos. Por isso, entende-se que proporcionar habilidades oferecidas por determinada atividade é procurar recursos que fazem com que o aluno aprenda de uma maneira mais prazerosa e precisa. Que fique bem claro que o jogo não é o todo, mas sim um facilitador do aprender matemático brincando.

\section{METODOLOGIA}

Para alcançarmos nossos objetivos propostos nessa pesquisa, utilizamos o método científico observacional-dialético e a pesquisa bibliográfica, pois em toda pesquisa de investigação se faz necessário adotar procedimentos observacionais para refletir acerca da realidade vivenciada de cada indivíduo e que os fatos acontecidos não podem ser realizados fora de um contexto cultural, político e socioeconômico do aluno. Podemos classificar nossa pesquisa como aplicada, pois, a partir de todos os dados coletados, obtivemos suporte e conhecimento para que a ideia fosse aplicada em sala de aula. 
A análise e interpretação de dados deu-se a partir das observações feitas em sala de aula nas escolas da rede pública. Analisou-se cinco escolas diferentes. Nelas, coletouse dados e informações para serem registrados na forma de um relatório que ofereceu suporte para a elaboração dos resultados. Apenas uma escola será apresentada neste artigo. A entidade escolhida foi a escola Charles Garcia. Considerou-se as percepções de 2 professores de Matemática e de 142 alunos do Ensino Fundamental do $6^{\circ}, 7^{\circ}, 8^{\circ}$ e $9^{\circ}$ ano do turno matutino. Os instrumentos utilizados para a coleta de dados foram:

1. Foi aplicado um questionário informativo e nele os alunos e professores foram solicitados a responder diferentes questões direcionadas para o foco principal do artigo;

2. Foi aplicado um questionário avaliativo que nos deu suporte para melhores informações acerca do nível de conhecimentos adquiridos pelos alunos no decorrer do período escolar.

A aplicação foi feita no dia 26 de julho de 2019, em um dia letivo, e contou com a participação $87 \%$ dos alunos presentes. O processo ocorreu de forma tranquila e todos os alunos participaram ativamente, recorrendo, até mesmo, à ajuda dos professores, pois nos auxiliaram na aplicação dos jogos, como mostra a tabela 1:

Tabela 1 - Dados referente a participação dos alunos nos jogos

\begin{tabular}{|l|l|l|l|}
\hline Série & $\begin{array}{l}\mathrm{N}^{\circ} \text { de alunos } \\
\text { Matriculados }\end{array}$ & $\begin{array}{l}\mathrm{N}^{\circ} \text { de Alunos } \\
\text { Entrevistados }\end{array}$ & Percentual \\
\hline $\mathbf{6}^{\circ}$ & 42 & 39 & $92 \%$ \\
\hline $\mathbf{7}^{\circ}$ & 45 & 40 & $88 \%$ \\
\hline $\mathbf{8}^{\circ}$ & 41 & 33 & $80 \%$ \\
\hline $\mathbf{9}^{\circ}$ & 35 & 30 & $85 \%$ \\
\hline Total & 163 & 142 & $87 \%$ \\
\hline
\end{tabular}

Fonte: Oliveira (2019) 


\section{ANÁLISE E DISCUSSÃO DOS RESULTADOS}

$\mathrm{Na}$ escola Charles Garcia lecionam no turno matutino dois (2) professores de Matemática, sendo que o professor $X$ leciona no $6^{\circ}$ e $7^{\circ}$ ano do Ensino Fundamental enquanto o professor $Y$ no $8^{\circ}$ e $9^{\circ}$ do Ensino Fundamental. Para que nossa pesquisa obtivesse êxito, procuramos informações sobre o tema proposto, com o objetivo de elaborar um diagnóstico acerca do ensino-aprendizagem da Matemática na realidade de nossa escola-campo, verificando, portanto, se os professores já adotavam a estratégia dos jogos didáticos para refletir sobre o cotidiano do aluno em sala de aula. De início foi elaborado um pré-questionário com 15 questões, e, a partir dele, discutiuse, avaliou-se e foi confeccionado o questionário oficial com 11 questões sendo 9 de múltipla escolha e as 2 restantes objetivas. Durante a aplicação os professores não se opuseram em responder e foram bastante atenciosos em nos receber.

Com a finalidade de incentivar os alunos e despertar o interesse nas aulas, procuram estratégias diferentes, usando, também, uma linguagem adequada e simples. Perguntamos, aos professores, se nas aulas já haviam utilizado materiais de apoio tais como: cartazes, quadra de esporte, jogos didáticos, embalagens diversas, visita à praças etc. Obtivemos, como resposta, que já utilizaram alguns dos itens e concordaram que esses recursos produzem efeito satisfatório no ensinoaprendizagem, mas que o tempo para desenvolver atividades dinâmicas é bastante curto e não seria possível desenvolvê-las com assiduidade.

Assim sendo, percebeu-se, ainda, nas respostas coletadas a partir do questionário, que eles acham interessante ensinar Matemática a partir de jogos e brincadeiras contextualizados, pois os alunos desenvolvem o raciocínio lógico-matemático de forma mais eficiente, o que facilita a compreensão dos conteúdos. Para isso, a escola oferece plena autonomia para o professor realizar suas atividades, porém não proporciona meio para tal, e, assim, os professores alegam a falta de material para ensinar o conteúdo proposto a partir dos jogos e brincadeiras, mas afirmaram que, em algumas vezes, apoiam-se nessa abordagem de ensino. 


\section{ANÁLISE DO QUESTIONÁRIO DOS ALUNOS}

A pesquisa amostral foi feita com alunos do $6^{\circ}, 7^{\circ}, 8^{\circ}$ e $9^{\circ}$ ano do Ensino Fundamental II da Escola Charles Garcia. A amostra contemplou 142 alunos, o que corresponde, aproximadamente, a $87 \%$ dos alunos dos ciclos entrevistados que estão regularmente matriculados na instituição. Assim como no questionário dos professores, elaboramos 20 questões, mas somente 10 foram submetidas às avaliações. Teve-se como objetivo descobrir possíveis deficiências no aprendizado matemático e os tipos de recursos didáticos utilizados para a abordagem dos conteúdos. A primeira pergunta investigou se os alunos achavam as aulas de Matemática interessantes. Sobre ela obtivemos, como resposta, o sim em maior índice percentual em todas as séries, como mostra a tabela 2. É notório, pelas suas respectivas respostas, que os alunos compreendem que a Matemática é importante e que está presente em seu cotidiano e quando o professor consegue lecionar de forma diferente, a Matemática se torna interessante, divertida e prazerosa de aprender (palavra do aluno).

Tabela 2 - você acha as aulas de matemática são interessante?

\begin{tabular}{|l|l|l|l|l|}
\hline & $\mathbf{6}^{\circ}$ série & $\mathbf{7}^{\circ}$ série & $\mathbf{8}^{\circ}$ série & $\mathbf{9}^{\circ}$ série \\
\hline SIM & 29 & 32 & 24 & 27 \\
\hline NÃO & 0 & 0 & 0 & 0 \\
\hline ȦS VEZES & 10 & 9 & 8 & 3 \\
\hline
\end{tabular}

Fonte: Oliveira (2019)

O segundo item abordado questionou se os professores utilizam exemplos do cotidiano para a explicação dos conteúdos matemáticos. As suas respostas demostram que eles, em alguns momentos da aula, utilizam-se exemplos dessa natureza, como ressalta o gráfico 1 . 
Gráfico 1 - Segundo item do questionário

\section{Durante a aplicação de alguns conteúdos de matemática o professor utiliza exemplos do cotidiano?}

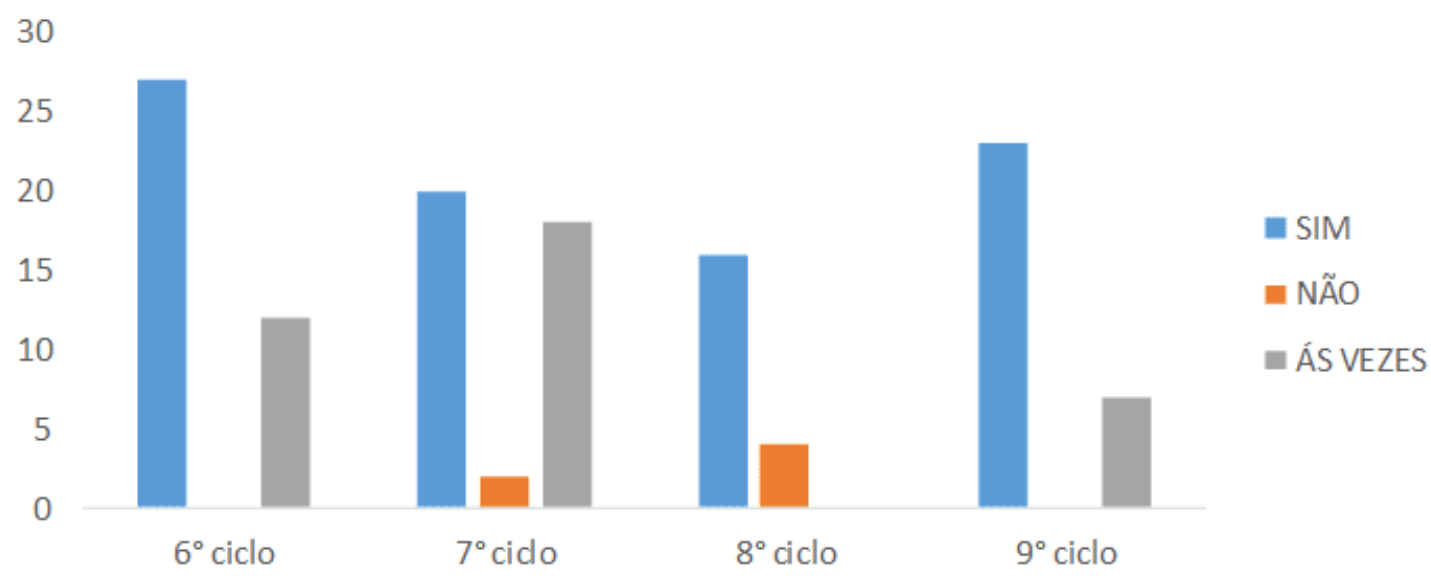

Fonte: Oliveira (2019)

Foi perguntado, também, se, em algum momento das suas aulas, o professor fazia uso de jogos didáticos, brincadeiras ou de qualquer tipo de ludicidade para abordar os assuntos matemáticos. Obtivemos não como resposta quase que de forma unânime, como mostra a tabela 3.

Tabela 3 - Você, como professor de Matemática, faz uso de jogos, brincadeiras ou qualquer tipo de ludicidade para abordar os conteúdos?

\begin{tabular}{|l|l|l|l|l|}
\hline & $\mathbf{6}^{\circ}$ série & $\mathbf{7}^{\circ}$ série & $\mathbf{8}^{\circ}$ série & $\mathbf{9}^{\circ}$ série \\
\hline SIM & 4 & 3 & 2 & 2 \\
\hline NÃO & 30 & 21 & 15 & 12 \\
\hline ÀS VEZES & 6 & 17 & 12 & 16 \\
\hline
\end{tabular}

Fonte: Oliveira (2019)

Nosso questionário procurou buscar informações acerca educando, visando, descobrir se ele gostaria que o professor utilizasse jogos e brincadeiras para ensinar 
Matemática. As respostas foram unânimes: eles têm plena conviç̧ão que a partir da inclusão dos jogos e brincadeiras conseguiriam aprender e compreender com maior facilidade. Outra questão foi abordada quanto à maneira de como eles gostariam que fossem as aulas de Matemática. Obtivemos respostas bastante variadas. No entanto, as respostas mais comuns enfatizaram que seria interessante se os professores usassem os jogos e brincadeiras, explorassem mais os recursos didáticos e tivessem melhor domínio desses recursos na sala de aula. O questionário estendeu-se com outras questões que não citaremos aqui por conta do espaço.

\section{ANÁLISE E DISCUSSÃO DOS RESULTADOS}

Os recursos metodológicos utilizados pelos professores como brincadeiras e jogos devem ser compreendidos não apenas como um simples instrumento recreativo que conduzirá a aprendizagem dos alunos, mas como um facilitador para o desenvolvimento do raciocínio do aluno, colaborando, dessa forma, para desbloqueio que eles possam vir a apresentar sobre temas e abordagens matemáticas. Sua inserção tem como objetivo fazer com que o aluno venha a se interessar pela disciplina, pois muitos apresentam dificuldades para a compreensão, mudando, assim, a rotina da aplicação dos conteúdos e despertando o interesse de aprender. Ao analisar os jogos na educação, podemos citar alguns benefícios que esses trazem se forem introduzidos corretamente nas aulas de Matemática, tais como: interação social; desenvolvimento de um ser criativo; desenvolvimento da competitividade; assimilação com maior e melhor facilidade dos conteúdos e detecção de alunos que estão com maiores dificuldades.

Além disso, devemos tomar alguns cuidados na escolha desses jogos e brincadeiras para não as tornar algo obrigatório. O jogo utilizado realizado na escola com os alunos foi o jogo da potenciação, que buscou proporcionar, aos alunos, uma aprendizagem mais dinâmica, divertida, descontraída e significativa, desenvolvendo, então, o raciocínio e estabelecendo relações entre o jogo e os conceitos matemáticos. O material utilizado foi 1 roleta de disco de pizza, fichas contendo exemplos de potência e um dado. A turma foi dividida em 6 grupos e cada grupo elegeu um representante. Cada representante deveria escolher um número de 1 a 6 e o professor ficou com o 
dado até que ele jogasse. $\mathrm{O}$ jogo foi iniciado com o grupo que tirou o maior número e assim sucessivamente. Para jogar o representante do grupo deveria girar a roleta e aguardar parar. Em seguida, o aluno deveria ir ao quadro e responder a potência sorteada. Caso acertasse, jogaria novamente, caso errasse, passaria a vez para o próximo grupo. Ganhou o jogo o grupo com o maior número de acertos.

Figura 1 - Jogo de potenciação

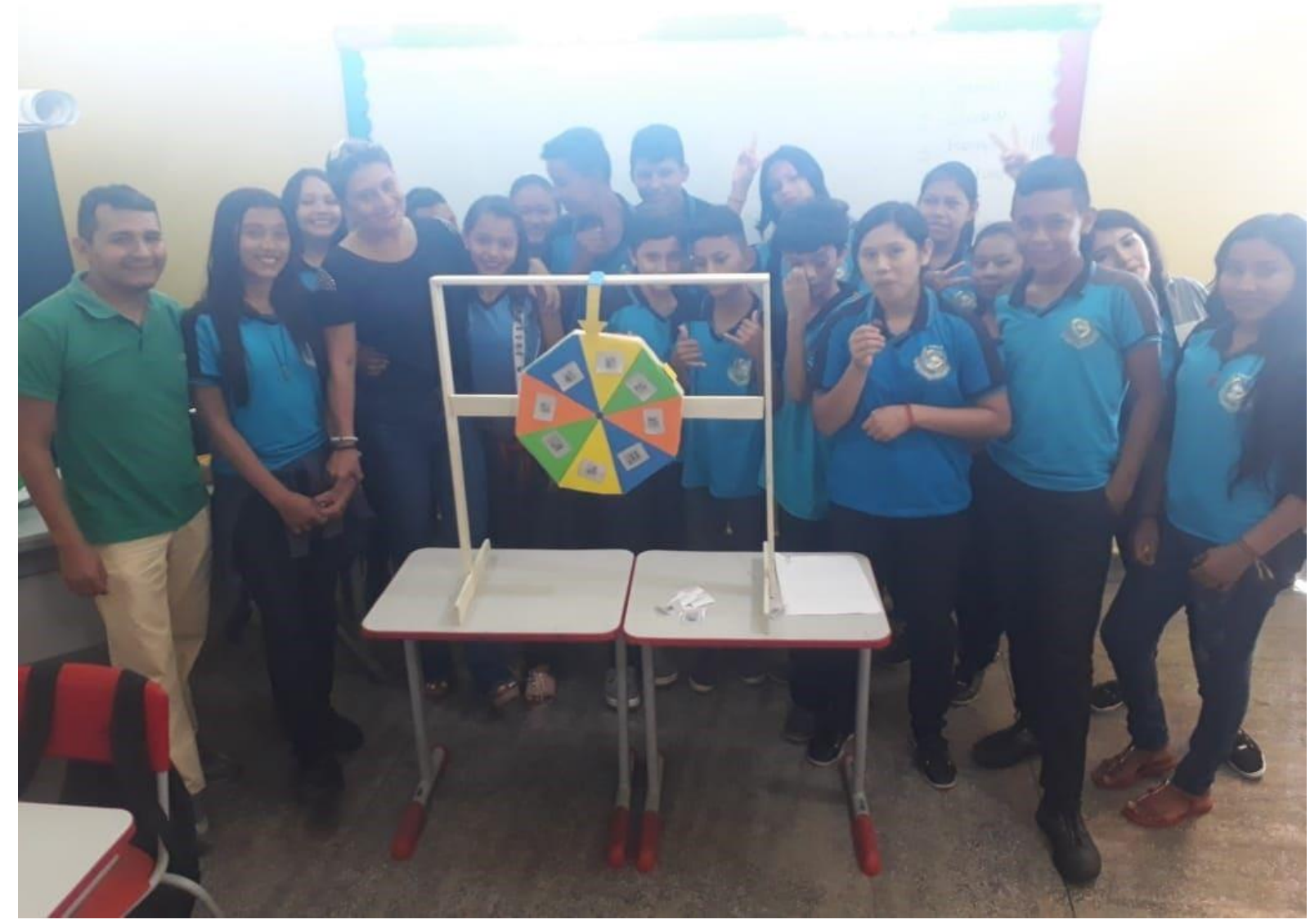

Fonte: Oliveira (2019)

Em resultado disso, obtivemos, como resposta, vários pontos positivos como: divertimento, clareza, compreensão, sociabilidade, agilidade, criticidade e ouros e em momento houve fuga dos objetivos a serem alcançados. 


\section{CONSIDERAÇÕES FINAIS}

Por intermédio dos jogos e brincadeiras contextualizados e a relação com o cotidiano tivemos como objetivo o aprendizado matemático. Observamos que o ensino dessa disciplina não está ligado somente ao uso de conceitos teóricos e muito menos com os materiais didáticos dos alunos. Com isso, mediante a perspectiva de possíveis soluções da problemática, procuramos, neste artigo, discutir sobre tópicos solucionadores para tal. Na pesquisa, percebemos que o ensino da Matemática é feito, sempre, de forma precária, e, assim, desrespeita os recursos didáticos, em especial os jogos e brincadeiras que são facilitadores do processo de ensinoaprendizagem do aluno. A forma como o professor trabalha as atividades práticas, como os jogos e brincadeiras é importância, pois auxilia os alunos na construção da sua afetividade, a ampliar sua linguagem, o seu conhecimento, a sua competência psicomotora, enfim, o seu desenvolvimento cognitivo e sócio relacional.

Nesta abordagem, observou-se que o jogo é um recurso pedagógico de grande importância para que seja possível fazer com que o aluno experiencie uma aprendizagem significativa. Os jogos e brincadeiras são instrumentos facilitadores da aprendizagem do aluno pré-adolescente e têm sido objetos de estudo e análise por parte de muitos estudiosos que pensam as questões relativas à educação e à aprendizagem. Concluímos que a pesquisa foi muito importante para nossa formação acadêmica, pois, para que pudesse ser realizada, tivemos que buscar embasamento teórico em diferentes obras e trabalhos realizados bem como informações sobre diferentes recursos para o ensino matemático, nos atualizando, sempre, sobre o assunto abordado. Podemos afirmar que: o professor precisa sempre se atualizar constantemente buscando, para isso, novas perspectivas pedagógicas para a construção do conhecimento próprio e de seus educandos.

\section{REFERÊNCIAS}

AMBROSIO, U. Educação Matemática da Teoria a Prática. 12ª . ed. Campinas: Papirus, 1996. 
ARANÃO, I. V. D. A Matemática através de Brincadeira e jogos. 5ª ed. Campinas: papiros, 2004.

CARRAHER, T. N.; SCHLIEMANN, A. Na vida dez na escola zero. 8ª ed. São Paulo: Editora Cortez, 1994.

FREIRE P. Pedagogia da Autonomia. Saberes Necessários à Prática Educativa. São Paulo: Paz e Terra, 1996.

LUCENA, F. de. Jogos e Brincadeiras na Educação Infantil. Campinas: Papirus, 2004.

SILVA, M. Jogos Educativos. Campinas: Papirus, 2004.

Enviado: Setembro, 2019.

Aprovado: Março, 2020. 